\title{
REALISMO, TÁCTICA Y ESPECTÁCULO CRÍTICA DE LO COTIDIANO EN LA SUBURBIA DE VENTURI Y SCOTT BROWN
}

\author{
David Franco
}

El principal objetivo de este artículo es el de examinar, desde una nueva perspectiva, las ideas que durante los años setenta propusieron Robert Venturi y Denise Scott-Brown en defensa de la suburbia americana. Para ello se traslada la reflexión desde el ámbito de lo simbólico -en que lo enmarcaban sus autores- al de la vida cotidiana, dentro del cual el artículo se centra en la polarización de las prácticas de lo cotidiano -propuesta por Michel De Certeau-entre tácticas y estrategias, así como en las ramificaciones socio-políticas de las mismas.

Palabras clave: Suburbia, Venturi, Scott Brown, vida cotidiana, tácticas

Keywords: Suburbia, Venturi, Scott Brown, Everyday Life, Tactics

El impacto de la obra teórica de Robert Venturi y Denise Scott Brown en la construcción de una alternativa crítica al paradigma arquitectónico moderno es incuestionable. En su introducción a Complejidad y Contradicción en Arquitectura, Vincent Scully llega a comparar la importancia del primer libro de Venturi con Vers une architecture, y al propio Robert Venturi con Le Corbusier, argumentando que ambos fueron capaces, en sus respectivos contextos históricos, de liberarse de las pautas de pensamiento y las modas aceptadas por sus contemporáneos $^{1}$. Por su parte, Rafael Moneo, en el capítulo que dedica a Venturi y Scott Brown en su libro Inquietud Teórica y Estrategia Proyectual, subraya la influencia que la pareja tuvo en la formulación de un mensaje liberador, especialmente para los arquitectos más jóvenes, en una época en que el lenguaje arquitectónico moderno se había convertido en el vocabulario preferido por las instituciones, los promotores y la industria.

En Complejidad y Contradicción en Arquitectura -escrito tras una estancia de dos años en la Academia Americana en Roma- Venturi analiza una miríada de ejemplos de arquitectura renacentista, barroca, y neoclásica para ilustrar las lecciones de riqueza y ambigüedad que la experiencia arquitectónica premoderna podía proporcionar para la superación del "lenguaje puritano y moral de la ortodoxia moderna"2.

En contraste, su segundo libro -Aprendiendo de Las Vegas-, escrito ya junto a su compañera Denise Scott Brown y Steve Izenour, prescinde de la sutil erudición del primero para construir una apología de la arquitectura más ordinaria de Estados Unidos: el rastro físico de décadas de modernización socio-económica y suburbanización del territorio, cuyo epicentro Venturi sitúa en la ciudad de Las Vegas. Si bien el libro constituye un intento -explícitamente anti-moderno- de reconectar la arquitectura a una realidad específica, es difícil discernir en qué medida ha sido influyente -tras su masiva difusión- en la legitimación y consiguiente aceleración de los procesos que describe. En cualquier caso, tras una mirada al paisaje urbano de la América contemporánea, no cabe duda de que la inmensa mayoría de los edificios públicos y comerciales construidos en las ultimas décadas responden de un modo u otro a la noción de 'decorated shed' definida en Learning From Las Vegas. Sin embargo, una salvedad fundamental separa la realidad suburbana contemporánea de la descrita -y defendida- por Venturi y Scott Brown. Donde la pareja veía riqueza, espontaneidad y vitalidad, la América suburbana ha producido homogeneidad y banalidad. Idénticas cadenas de restaurantes -Applebee's, Ruby Tuesday-, de centros comerciales y supermercados -Walmart, Target, Costco, Kmart-, salpican de manera indiferente la exuberante diversidad de los paisajes de Norteamérica.
1. SCULLY, Vincent, "Introduction", en Complexity and Contradiction in Architecture, Moma, New York, 1967, p. 9.

2. VENTURI, Robert, Complexity and Contradiction in Architecture, Moma, New York, 1967. 

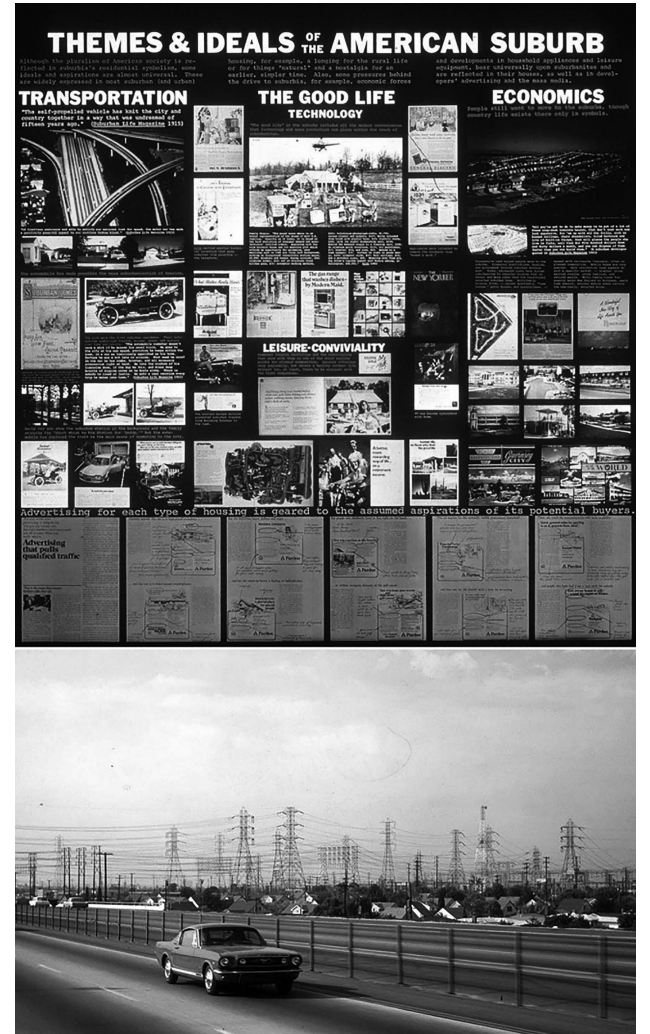

Fig. 1. Uno de los paneles de la exposición Signs of Life, dedicado al paisaje suburbano en Estados Unidos. Desine Scott Brown y Robert Venturi, 1976. Fuente: VSBA Architects. And Planners.

3. En gran medida, 'Aprendiendo de Las Vegas' puede leers como un manifiesto a favor de la recuperación de lo simbólico en el ámbito de la arquitectura, tal y como refleja e subtítulo original de la publicación: 'El simbolismo olvidado de la forma arquitectónica'.

4. LEFEBVRE, Henri, Critique of Everyday Life: The Three Volume Text, Verso, Londres, 2014.

5. MCLEOD, M., 'Henri Lefebvre's Critique of Everyday's Life', en HARRIS, Steven; BERKEE, Deborah (eds.), Architecture of the Everyday, Princeton Architectural Press, New York, 1997, p. 13.

6. El primero de los tres volúmenes de su monumental "Critique de la vie quotidienne" se publicó en 1947, el segundo en 1961 y el tercero en 1981.

7. HIGMORE, Ben, Everyday Life and Cultural Theory, Routledge, London, 2003, p. 145

8. Ibid.

9. Idem, p. 150.

10. DE CERTEAU, M., La invención de lo cotidiano I. Artes de Hacer, Universidad Iberoamericana, Méjico, 2000, p. XLIII.

11. Idem, p. 42.

12. Idem.
El propósito principal de este texto es, precisamente, el de abordar las ideas que Robert Venturi y Denise Scott Brown propusieron en defensa de la suburbia americana al largo de la década de los setenta, desde una nueva perspectiva crítica que las haga relevantes vistas desde el presente. Para ello, y con el objeto de obtener un enfoque diferente, que se acerque de manera efectiva a la realidad suburbana, desplazaré el área de reflexión desde la noción de 'lo simbólico', que ellos situaban en el centro de su proyecto teórico 3 , a la de 'lo cotidiano'. La vida cotidiana moderna, tal y como anticipaba Henri Lefebvre ${ }^{4}$, contiene dentro de sí los síntomas inconfundibles de la mercantilización de la esfera de lo colectivo, cuyo ejemplo primordial es -como registraba Venturi- la proliferación de imágenes simbólicas en el espacio público.

Sin embargo, tal y como sostiene el propio Lefebvre, la misma cotidianidad moderna posee un extraordinario potencial innovador, ya que, paradójicamente, contiene espacios en los que emergen contenidos culturales con capacidad para superar dicha mercantilización. Como explica Mary McLeod, la noción de vida cotidiana en Lefebvre es, antes que nada, paradójica: aunque transmite una imagen de estabilidad, es transitoria e incierta; aunque está gobernada por la monótona marcha del tiempo lineal, se redime por la renovación del tiempo cíclico de la naturaleza; y si bien está controlada por el racionalismo tecnocrático y el capitalismo, se posiciona fuera de ellos 5 .

La concepción paradójica y dialéctica que Lefebvre construye sobre lo cotidiano ${ }^{6}$, tiene continuación en la obra de Michel De Certeau. Según Ben Highmore, la mayor diferencia entre las nociones de cotidianidad que ambos manejan no se encuentra por tanto en el paradigma filosófico que adoptan, sino en "el nivel de sensibilidad" con el que los dos acometen el concepto de lo cotidiano. Lefebvre afronta la cuestión desde la teoría crítica, partiendo de la idea de que lo cotidiano en el mundo moderno -y aún mas en la posmodernidad-corresponde a "una condición de alienación". Aunque admite que la vida diaria ofrece momentos de superación de si misma, el énfasis siempre queda sobre lo indiscutible de la colonización de lo cotidiano por parte de la cultura de consumo?.

De Certeau, en cambio, construye su idea desde una perspectiva política más elíptica, a partir de lo que podríamos denominar una 'resistencia creativa' al status quo. Una resistencia nacida desde el interior mismo de las prácticas de lo cotidiano, pero que antes que inventar opera con lo que ya existe, apropiándose de los productos del sistema en vez de rechazarlos. Así, según De Certeau, "a una producción racionalizada, tan expansionista como centralizada, ruidosa y espectacular, corresponde otra producción", que surge del mismo acto de consumir y que "se encuentra dispersa pero se insinúa en todas partes, silenciosa y casi invisible, pues no se señala con productos propios sino en las maneras de emplear los productos impuestos por el orden económico dominante" ${ }^{10}$.

Esta versión más matizada de lo que significa el consumo -una aceptación negociada de la cultura del capitalismo-, puede ser extraordinariamente útil para revisar, como nos hemos propuesto, la crítica a la obra de Venturi y Scott Brown. Con ese objeto me gustaría recurrir a dos conceptos complementarios que el mismo De Certeau propone como bases para explicar las relaciones entre una cultura dominante y prácticas de resistencia. Las estrategias, por un lado, se definen como los modos de planificación y operación de las instituciones o, tal y como detalla el mismo De Certeau, como el "cálculo (o la manipulación) de las relaciones de fuerzas que se hacen posible desde que un sujeto de voluntad y de poder (una empresa, un ejército, una ciudad, una institución científica) resulta aislable"11. Las tácticas, por otro, constituyen las maneras en que cristalizan los procesos organizados al margen del pensamiento estratégico. Desde una perspectiva espacial, éstas se caracterizarían por la ocupación de espacios existentes, infiltrándolos con prácticas alternativas a las organizadas desde el poder, pero que ni se enfrentan a éste, ni producen mundos diferentes. En cambio, utilizan para sus fines los materiales -fácilmente disponibles- producidos por las prácticas dominantes. Así, según De Certeau, frente a las estrategias que organizan las acciones del sistema dominante implementando la "racionalidad política, económica o científica" 12 y que ocupan la mayor parte del tablero de juego, se hace imprescindible la creación de tácticas que abran grietas a través de las cuales se pueda reactivar la vida cotidiana, mediante nuevas formas de creatividad e inventiva. 


\section{REALISMO Y ESPECTÁCULO EN LEARNING FROM LAS VEGAS}

Parece claro que en las narrativas urbanas y arquitectónicas de Aprendiendo de Las Vegas, hay una admisión tácita de la lógica económica y social del capitalismo americano moderno. Sin embargo, a pesar de que el texto defiende la viabilidad estética del gran impulso privatizador de la ciudad americana de mediados de siglo -la explosión suburbana que fue apoyada tanto por la política federal ${ }^{13}$, como por las élites empresariales-, hay un continuo posicionamiento en contra del status quo y a favor de las clases sociales más desfavorecidas. Estas críticas nunca se formulan de manera abierta sino, por una parte, como una denuncia al viejo establishment arquitectónico moderno, y por otra, como una preocupación constante por incluir la cuestión social como factor esencial dentro de la reflexión arquitectónica.

Un ejemplo de lo primero es la alusión crítica que Denise Scott Brown hace del economista liberal John Kenneth Galbraith por su ataque en un artículo de Life Magazine al absurdo medioambiental de la ciudad del automóvil y a sus nefastas consecuencias estéticas. En concreto, Galbraith concentra su crítica en la proliferación de construcciones banales y de poca calidad como gasolineras y vallas publicitarias, "la peor y más inútil excrecencia de la civilización industrial"14. No parece casual que el personaje atacado fuera conocido por su defensa de una mayor intervención estatal en la economía, habiendo además mostrado una especial preocupación por el crecimiento desordenado de la cultura del consumo ${ }^{15}$. En realidad, la figura de Galbraith le sirve a Scott Brown para arremeter contra "sus compañeros"16, las verdaderas bestias negras del posmodernismo: "los viejos radicales arquitectónicos que todavía manejan las Comisiones de Bellas Artes de América"17. Es decir, los que tomaban las decisiones sobre la estética y la forma de la ciudad manteniendo todavía el ideario moderno como receta urbana esencial ${ }^{18}$.

Un ejemplo de lo segundo -la continua preocupación por incluir lo social como parte de lo arquitectónico-, lo encontramos en el mismo artículo $^{19}$, cuando Scott Brown deja clara la preeminencia del nivel de riqueza como elemento definitorio del modelo residencial, advirtiendo que las clases más bajas no viven voluntariamente en bloques de pisos, del mismo modo que las clases medias no lo hacen en los barrios suburbanos, por lo cual, concluye Scott Brown "quizás el estilo georgiano es menos pertinente para el habitante de un adosado que la renta del alquiler"20.

Este doble argumento es típico en Venturi y Scott Brown: el ataque a los viejos modernos por un lado, y la defensa de la estética de las clases medias y bajas por otro. Es aquí donde vislumbramos la intención de producir un movimiento táctico de resistencia que, reivindicando los contenidos de la ciudad suburbana, es decir, utilizando los 'materiales disponibles', produzca una superación del status quo arquitectónico. En palabras de De Certeau, "sin cesar, el débil debe sacar provecho de fuerzas que le resultan ajenas" realmente afirmar que el giro anti-moderno y pro-suburbano que Venturi y Scott Brown proponen, se pone, efectivamente, del lado de los débiles?

Para la historiadora Deborah Fausch la respuesta a esta pregunta es indudablemente positiva, ya que, según ella, la formulación de una nueva belleza de lo ordinario a través de la reinterpretación de la realidad suburbana contiene una carga crítica implícita. Esta es la razón, según Fausch, por la cual "Venturi y Scott Brown caracterizan su investigación de un nuevo vernáculo urbano como una forma de realismo"22. No sólo por su metodología o por su compromiso con formas urbanas existentes sino, especialmente, por sus connotaciones políticas y sociales, que lo vinculan directamente a "la tradición realista literaria y pictórica del siglo XIX francés", cuya descripción de las prácticas de la vida de las clases trabajadoras se entendió como tan revolucionaria que se excluyó de "los museos y salones"23. Debora Fausch explica que no se puede concebir el interés de Venturi por el paisaje existente sin considerar su vinculación con la tradición estética realista.

\section{ENTRE LO TÁCTICO Y LO ESTRATÉGICO}

Aunque resulta discutible establecer dicho paralelismo -el París revolucionario de mediados del siglo XIX frente a la Suburbia americana de mediados del XX- sin sacrificar la

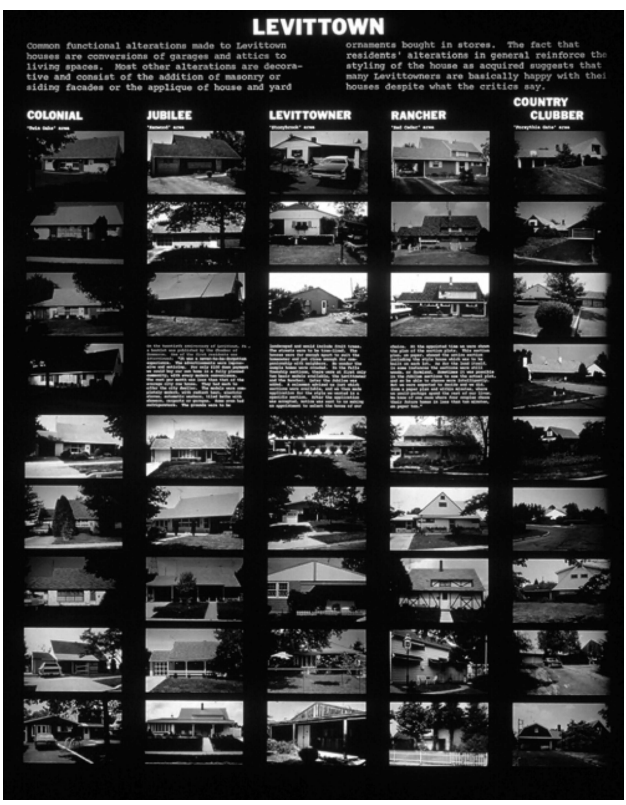

Fig. 2. Páginas interiores de Life. En el artículo 'Speaking of pictures' se reflexionaba sobre la sobreabundancia de señales comerciales y anuncios en el paisaje suburbano de Estados Unidos. Fuente: Life Magazine.

13. El apoyo estatal al proceso de suburbanización se materializó, entre otros elementos, a través de leyes que promovían la propiedad frente al alquiler, como el Service Men's Readjustment Act, conocido como G.I. Bill y que fue aprobado en 1944, dando ventajas fiscales a numerosísimos veteranos de la Segunda Guerra Mundial para la adquisición de nuevas viviendas. Véase: JACKSON, Kenneth, Crabgrass Frontier: The Suburbanization of the United States, Oxford University Press, New York, 1985.

14. GALBRAITH, John Kenneth, "To My New Friends in the Affluent Society-Greetings", en Life Magazine, March 27, 1970, citado en SCOTT BROWN, Denise, 'Learning From Pop', ver nota 16.

15. Véase: GALBRAITH, John Kenneth, The Affluent Society, Houghton Mifflin Harcourt, New York, 1998. Publicado originalmente en 1958.

16. SCOTT BROWN, D., 'Learning From Pop' en HAYS, M., (ed.) Architecture Theory since 1968, MIT Press, New York, 2000, pp. 60-67.

17. Ibid.

18. En palabras de Scott Brown, "las agencias de planificación y urbanización que diseñan y construyen para las empresas públicas y privadas más grandes y son escuchados por los que toman las decisiones en la construcción de la ciudad". Ibid., p. 60.

19. SCOTT BROWN, Denise, 'Learning From Pop, op. cit.

20. Ibid., p. 62.

21. DE CERTEAU M., op. cit., p. L.

22. FAUSCH, Deborah, "Ugly and Ordinary: The Representation of the Everyday" en Architecture of The Everyday, ed. Steven Harris y Deborah Berke, Princeton Architectural Press, New York, 1997, p. 94.

23. Ibid. 
consistencia histórica, es posible rastrear una cierta similitud metodológica entre el 'realismo posmoderno' y el realismo francés del XIX. Al igual que los protagonistas de éste, Venturi y Scott Brown conciben "la investigación empírica de la realidad" 24 como una manera de confrontar dicha realidad desde una perspectiva nueva, utilizando "una técnica de shock estético como crítica social" 25 . Los pintores y escritores realistas, al igual que los Venturi, alimentaron una polémica que iba más allá de sus obras, proponiendo un nuevo lenguaje formal que renunciaba a la idealización de la realidad.

Podemos entonces interpretar la mirada que Learning from Las Vegas propone, como una táctica que opera a través de la infiltración de imágenes cuyo objetivo es provocar un cambio en el punto de vista del espectador. Es bien sabido que Venturi y Scott Brown, al igual que los Smithson y Nigel Henderson, por un lado, y los artistas Pop americanos por otro, mostraban un gran interés por técnicas de comunicación análogas a las utilizadas en el mundo de la publicidad. Por ello, es significativo que cuando defienden una arquitectura más cercana a sus usuarios reales, lo hagan en términos de mercado:

"Ningún constructor o promotor en su sano juicio podría anunciar: Estoy construyendo para el Hombre. Construye para un mercado, para un grupo de personas definidas por su nivel de ingresos, su edad, su composición familiar y su estilo de vida"26.

Detrás de este léxico - mercado, estilo de vida y publicidad-, se oculta una intención táctica: se trata de extraer energías del modelo dominante para proponer algo distinto. Sin embargo, como operación táctica, algo no funciona del todo. Hay un extraña desproporción entre lo que se quiere superar y lo que se utiliza. Para construir una resistencia estética capaz de superar al viejo establishment de la arquitectura moderna, se instrumentaliza -legitimándola- lo que Debord había denunciado en la Sociedad del Espectáculo: la transformación de la vida cotidiana en espectáculo.

Fred Koetter, entonces un joven arquitecto colaborador de Colin Rowe, publicó en 1974 una de las críticas más lúcidas a Learning from Las Vegas en la que insiste en las consecuencias de la 'espectacularización' de la cultura que Venturi y Scott Brown, si quiera por mera abstención, admiten como parte sustancial en la estética de Las Vegas. Según Koetter, la industria del entretenimiento moderna, de la que Las Vegas es un ejemplo, se caracteriza por suministrar "emociones baratas y fantasías escapistas" 27 que, por desgracia, en una sociedad cada vez más orientada al consumo, han ido sustituyendo a lo que antes se identificaba como "vida cultural"28. Esta nueva forma de cultura,

"[...] presenta simulaciones fáciles de propósitos difíciles y serios, y muestra un sustituto precocinado y adelgazado de la realidad que, presentado como una dieta básica, poco a poco rompe el espíritu crítico, embota los sentidos y cada vez más apunta hacia la imposición de una sociedad en la que lo auténtico, y todo el esfuerzo que se requiere para su comprensión, ya no es necesario o incluso no es reconocido" 29 .

Por tanto, según Koetter, es imposible estudiar el urbanismo y la arquitectura de Las Vegas de manera autónoma, como hacen Venturi y Scott Brown, sin entender cuestiones como esta, relativas a su realidad subyacente. Es en esta inconsistencia, en la cohabitación entre la resistencia táctica y el discurso estratégico de la sociedad del espectáculo, donde se define el núcleo del realismo de Venturi y Scott Brown. Sus propuestas son tácticas en la medida en que reivindican los residuos espaciales de la economía capitalista frente a la -todavía influyente-utopía moderna. Si vemos estos residuos como fragmentos sin una ideología totalizadora, como el producto de las prácticas de lo cotidiano en la América suburbana, en ese caso, la defensa de su legitimidad es, sin duda, un modo de resistencia. De manera similar, en su ataque contra la ortodoxia moderna -especialmente en contra de la última modernidad americana-, sin duda el trabajo de Venturi y Scott Brown es también de resistencia. No olvidemos que eran, precisamente, arquitectos como Rudolph o Pei, a los que se enfrentaban los Venturi, los responsables de los monumentos arquitectónicos modernos que encarnaban la Pax Americana desde el final de la Segunda Guerra Mundial.

Recordemos que el modo de operar táctico carece de un espacio que le pertenezca, siempre se sitúa en el campo del enemigo, ya que "no cuenta con la posibilidad de darse un proyecto global ni de totalizar al adversario en un espacio distinto, visible y capaz de hacerse objetivo" ${ }^{30}$. La retórica heroica de la guerra fría tiene su origen, entre otros factores, en la 


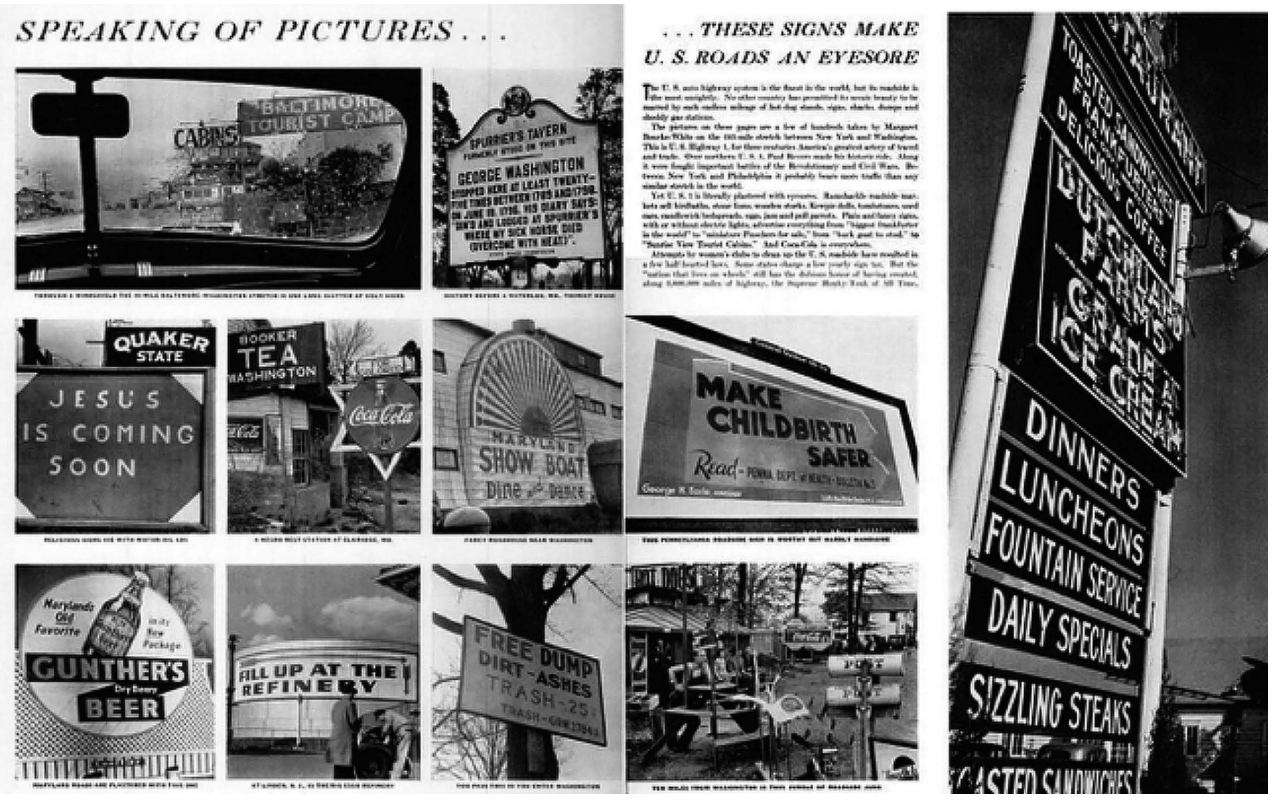

prosperidad del sistema productivo del Estados Unidos de posguerra, que se materializa en la monumentalidad moderna: es la arquitectura del poder de lo visible, de lo estratégico que ocupa todo el espacio de la cultura arquitectónica oficial.

Paradójicamente, esta misma prosperidad es la causa del crecimiento desordenado, a base de fragmentos, de la ciudad suburbana, así como de toda una colección de nuevas formas arquitectónicas asociadas a la misma. Lo que interesa a los Venturi es el estudio de dichas formas y su caótica colonización del paisaje americano. Pero no es posible concebir estos fragmentos, ni los modos de vida que se desarrollan en ellos, sin tener en cuenta operaciones de gran escala que necesitan del poder del sistema dominante para hacerse realidad. Un ejemplo fundamental de dichas operaciones es la construcción de las primeras grandes autopistas interestatales a partir de $1956^{31}$, proporcionando un nivel de movilidad y flexibilidad inimaginable en Europa. Otros dos ejemplos, son, por un lado el desarrollo de la industria petrolífera y su poder como lobby en Washington y, por otro, las nuevas promotoras de viviendas unifamiliares. Los grandes developers, como los hermanos Levitt, fueron esenciales en la introducción de un nuevo modelo que integraba todos los pasos del proceso de creación de nuevos asentamientos: la adquisición de terreno, la construcción de infraestructura urbanas, el diseño arquitectónico, la construcción de la vivienda e, incluso, la adquisición de los electrodomésticos y otras tecnologías necesarias para el estilo de vida suburbano.

A pesar de la fragmentación de los barrios suburbanos de los cincuenta y sesenta, -aparentemente construidos de manera orgánica y desordenada-, tanto los medios productivos como los agentes implicados en el proceso tendieron rápidamente a una progresiva acumulación y centralización de recursos. La ligereza en la regulación urbana local y el escaso control federal sobre estos procesos, que podría parecer, de nuevo, que fueron creados con gran espontaneidad, deja paso a las leyes del mercado y al control de conglomerados empresariales cada vez más poderosos e influyentes ${ }^{32}$.

\section{RESISTENCIA, PROVOCACIÓN O SIMULACRO DE REVOLUCIÓN}

¿Podemos entender el 'vernáculo comercial', el 'decorated shed' y las demás propuestas incluidas en Learning from Las Vegas como formas de resistencia arquitectónica en el terreno de juego de las grandes operaciones del sistema dominante? O, en cambio, ¿son, sencillamente, el resultado directo de las mismas? Esta cuestión se mantiene abierta, al menos, a dos posible, interpretaciones. Por un lado, la de Deborah Fausch, que considera que son una forma de realismo y, por tanto, una manera de resistencia estética; y, por otro, la de Fred Koetter, que los asocia a las patologías de la sociedad de consumo.
Fig. 3 Uno de los paneles de la exposición Signs of Life, dedicado a Levittown. Desine Scott Brown y Robert Venturi, 1976. Fuente VSBA Architects and Planners.
31. Véase: WEINGROFF, Richard, 'Federal-Aid Highway Act of 1956: Creating the Interstate System' en Public Roads, Vol. 60, n. 1, Summer, 1996.

32. Véase: JACKSON, Kenneth, Crabgrass Frontier: The Suburbanization of the United States, Oxford University Press, New York, 1985. 
Ante esta disyuntiva, no parece arriesgado afirmar que, en contra de lo que Venturi y Scott Brown sostienen, su programa arquitectónico no emana directamente de la realidad construida de Las Vegas, o de la ciudad suburbana en general, sino que, si existe como forma de resistencia, ésta se concentra en la interpretación propuesta por ellos mismos. En otras palabras, lo que se plantea en Learning from Las Vegas no puede ser entendido como una respuesta crítica al sistema de valores moderno, o a las distintas encarnaciones estéticas del mismo, sino que se limita específicamente al ámbito de lo disciplinar y, dentro de éste, al de lo formal. Es significativo que, desde el principio del libro, se percibe el esfuerzo por mantener un tono de provocación que lo enlaza a ciertas vanguardias de principios de siglo. Como leemos en uno de los primeros párrafos, "aprender del paisaje existente es la manera de ser un arquitecto revolucionario"33.

Al posicionarse como una nueva oleada de vanguardia, aunque más abierta y tolerante, Venturi y Scott Brown sugieren que su trabajo encierra, como el de los primeros arquitectos modernos, una inquietud social esencial. Así, cuando se refieren al "paisaje existente", parece que, al igual que Le Corbusier, no se limitan a la estructura física de la ciudad sino, sobre todo, a sus dinámicas culturales, económicas y sociales. En clara oposición a esta teoría, que convierte al posmodernismo de Venturi en portador de contenidos sociales y políticos, Mary McLeod subraya la limitación de éste a lo formal y cómo, a pesar de la reconexión con la realidad social que Venturi parece sugerir, esta condición limitada lo distingue nítidamente de la inquietud política de las vanguardias modernas:

\begin{abstract}
"El movimiento moderno era entendido, tanto por sus primeros arquitectos como por sus historiadores, como intrínsecamente relacionado con nuevas técnicas, con la cultura de masas, y con un papel social más amplio. Y si los defensores posmodernos han producido su propia versión más reduccionista y monolítica de la arquitectura moderna, ésta es una que afirma, incluso exagera, las preocupaciones sociales del movimiento moderno".
\end{abstract}

De este modo, explica McLeod, la polaridad comúnmente aceptada entre modernismo/ autonomía artística y posmodernismo/cultura de masas, pierde todo su sentido. De hecho, las corrientes posmodernas, tanto historicistas como post-estructuralistas, pueden entenderse como un retorno a la arquitectura como actividad principalmente formal y artística, en claro rechazo del compromiso social característico del movimiento moderno ${ }^{34}$.

En una pequeña anécdota que narra Beatriz Colomina en el texto de la exposición Radical Pedagogies queda claro que el modo de trabajo de Venturi y Scott Brown en los setenta se basaba en la búsqueda intencionada de momentos de provocación estética cuyo efecto -casi secundario- era una crítica de carácter interno, despojada de auténtico contenido social. En 1970, dos años después del curso de proyectos en Yale cuyo trabajo resultó en la investigación y posterior publicación de Learning from Las Vegas, Venturi y Scott Brown prepararon otro curso, esta vez titulado Remedial Housing for Architects, en el cual, siguiendo lo iniciado en su investigación sobre Las Vegas, estudiaban las adiciones y transformaciones -casi siempre ornamentales- de los exteriores e interiores de las casas suburbanas de Levittown ${ }^{35}$. La presentación de los trabajos de curso en el verano de 1970 coincidió con un momento de extremada agitación estudiantil en Yale, y en universidades de todo el país, por las protestas en contra de la Guerra de Vietnam y por el reciente juicio a uno de los dirigentes del grupo de los panteras negras. En este ambiente, la reivindicación de la estética suburbana se percibía, sin duda, como una provocación por su implícito apoyo al mundo de suburbia, la encarnación arquitectónica del status. El propio Venturi relata cómo un autobús de estudiantes de Columbia se desplazó desde Nueva York hasta New Haven, para abuchear la presentación: "Nos sorprendíamos de cuánto los idealistas despreciaban a suburbia [...]. Tendemos a olvidar que lo que estábamos haciendo era extremadamente impopular"36.

Según ciertos defensores del trabajo de Venturi y Scott Brown, su auténtico valor se encuentra, precisamente, en su carácter provocador y subversivo, más allá del modelo de ciudad y de forma arquitectónica que defienden. Deborah Fausch ha llegado a afirmar que es en estos momentos de rebeldía, de cuestionamiento de lo que damos por sentado, cuando el posmodernismo de los Venturi se vuelve moderno: "esta corriente revolucionaria era parte de la estirpe intelectual de la modernidad, una peculiar combinación de estética y política que Venturi y Scott Brown llevan adelante en su propio trabajo"37. De manera similar, en su 


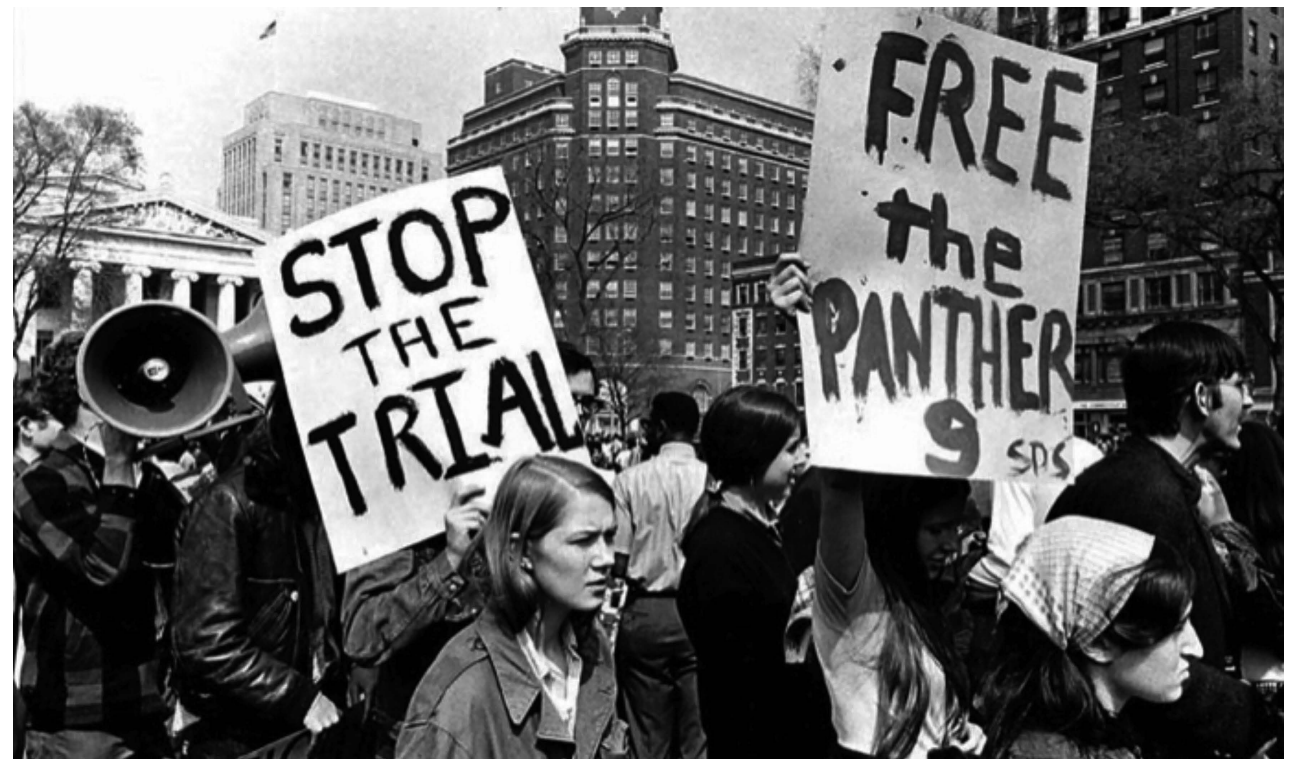

texto de introducción a Relearning from Las Vegas -titulado precisamente "Enseñanza como provocación" ${ }^{38}$-, Aron Vinegar y Michael Golec, atacan aquellas interpretaciones críticas, según ellos demasiado simplistas, que partiendo de planteamientos cercanos a la Escuela de Frankfurt, se concentran en la mercantilización estética de la ciudad que Venturi y Scott Brown promulgan. Para Vinegar y Golec la relevancia de la mirada de Venturi sobre la ciudad suburbana está en su intensidad más que en su consistencia, sea ésta arquitectónica o social. Utilizando como pie una cita del poeta trascendentalista estadounidense Ralph Waldo Emerson -"No es enseñanza lo que puedo recibir de otra alma, sino provocación"39- Golec y Vinegar aluden a la importancia del libro de los Venturi como llamada a la acción, más que como propuesta teórica o analítica, aduciendo que la verdadera fuerza de Learning from Las Vegas es que ejemplifica el verso de Emerson en cada una de sus líneas:

"El libro de Venturi, Scott Brown e Izenour opone el sentido ortodoxo de 'enseñanza'-los resultados y las ganancias derivadas de los mensajes enviados y mensajes recibidos-, contra el sentido perturbador de la 'provocación' en Emerson - una llamada a las armas, un medio para suscitar la acción-, en otras palabras, un desafío"

No hay duda de que el libro de los Venturi funcionó exactamente de esa manera: provocando las iras de unos, y animando a la acción directa a otros, aunque con un resultado desigual: si bien buena parte del mundo académico se mantuvo crítico a la propuesta de Venturi y Scott Brown ${ }^{41}$, la liberación posmoderna que promulgaban no tardó en verse materializada de manera masiva en la arquitectura comercial y hotelera de todo el mundo. Lo que quizá demuestra que, detrás de la provocación, más que una táctica de resistencia cuyo objeto es reinsertar las prácticas estéticas de lo cotidiano en la realidad, lo que hay -tal y como insinuaban los mismos Vinegar y Golec-, es la llamada a la acción de una arquitectura desprejuiciadamente visual, que bebe de la publicidad tanto como de la historia, y que estaba latente en el sistema estético del capitalismo americano. Entonces, ¿es el libro verdaderamente revolucionario? Y si lo es, ¿en qué medida responde a las problemáticas políticas y sociales de la suburbia americana?

Enlazando con la tradición de la Teoría Crítica de la Escuela de Frankfurt, Neil Leach cimenta una contundente crítica a Learning from Las Vegas, partiendo precisamente desde esta cuestión $^{42}$. Según él, la idea de que una arquitectura estéticamente radical es revolucionaria, tal y como Scott Brown y Venturi sostienen en el libro ${ }^{43}$, es una demostración del tipo de mirada que ambos practican sobre la realidad, privilegiando el valor de los signos mercantilizados - de la imagen significante con fuerza comercial-, sobre los efectos reales -tanto sociales como materiales- de la arquitectura. En el fondo, de este modo, se juega con la estetización completa del hecho urbano y arquitectónico, incluso de aquellos aspectos que no dependen de la forma o de la materialidad y que habitualmente se excluyen del discurso estético. Lo que conlleva, además, una estética de los aspectos sociales con el objeto de in-
Fig. 4. Imagen de las protestas estudiantiles a raíz del juicio por asesinato contra varios miembros del partido de los Panteras Negras en New Haven, en el verano de 1970. Fuente: Radical Pedagogies.
38. VINEGAR, Aaron; GOLEC, Michael, (eds.),VINEGAR, en Relearning from Las Vegas, University of Minnesota Press, New York, 2008

39. EMERSON, Ralph Waldo, 'The divinity School Address', en Ralph Waldo Emerson: Selected Essays, Lectures, and Poems, Bantam, New York, 1990, p. 110. Citado en VINEGAR, Aaron y GOLEC, Michael, op. cit., p. 14 40. Idem.

41. Según Deborah Fausch ésta crítica era, en general, más dura en Estados Unidos, ya que los europeos todavía sentían cierta fascinación por el mundo del consumo y la publicidad que llegaba de América, al cual todavía no se habían acostumbrado del todo. Vease: FAUSCH, D., op. cit., pp. 75-106. 42. LEACH, Neil, The Anaesthesis of Architecture, MIT Press, Cambridge, 1999, pp. 55-70.

43. Tal y como veíamos en una cita anterior en este mismo capítulo, en una de las primeras páginas del libro Venturi y Scott Brown declaran que "aprender del paisaje existente es la manera de ser un arquitecto revolucionario". Véase: VENTURI, R., SCOTT BROWN, D., IZENOUR, S., op., cit. p. 22. 
tensificar la idea arquitectónica. Lo político, lo subversivo, lo radical, se convierten, de este modo, en simulacros dentro de lo arquitectónico, en meros modos de apaciguar los aspectos potencialmente transformadores de la arquitectura. Por eso, tal y como Leach señala, paradójicamente,

"la cultura arquitectónica siempre será susceptible de una política reaccionaria, no a pesar de su fachada de radicalismo, sino precisamente por ella, una fachada que no es más que una imagen del radicalismo estético" ${ }^{44}$.

Como reflexión final, me gustaría sugerir que estas tácticas simuladas -estos simulacros de rebeldía estética- que evocan el impulso revolucionario de las vanguardias, son esenciales para entender las tendencias arquitectónicas anti modernas que arrancaron a finales de los años setenta. Las nociones complementarias de táctica y estrategia, que definen la vida cotidiana como esfera alternativa que permite un modo de resistencia aceptable por el sistema, nos proporcionan un marco teórico sólido para entender la transición entre modernidad y posmodernidad en arquitectura. A través de este marco podemos señalar, como he hecho en este texto, las inconsistencias de la teoría posmoderna -en la que destaca 'Learning from Las Vegas'- en cuanto a los aspectos sociales y políticos de lo arquitectónico. Pero además, también puede servirnos para establecer la manera en que una teorización de la arquitectura de lo cotidiano puede tener implicaciones socio-políticas y estético-formales que no se anulan las unas a las otras. Puede, por tanto, abrir caminos inexplorados para la arquitectura, a través de una nueva mirada a la esfera de lo ordinario pero, al contrario de cómo proponían Venturi y Scott Brown, sin asumir de manera acrítica la carga ideológica, las injusticias y la violencia social que dichas realidades conllevan.

David Franco. Obtuvo su título de arquitecto en la ETSAM en 2001, y recibió su doctorado en Historia de la Arquitectura y el Urbanismo en 2015, con una tesis sobre realismo, crítica y vida cotidiana. Desde 2014 es profesor titular de Historia y Teoría de la Arquitectura en la Universidad de Clemson en Carolina del Sur (USA), habiendo desarrollado su carrera docente previamente en la Universidad de Idaho y en la Universidad San Pablo CEU de Madrid. Sus proyectos han sido reconocidos con primeros premios en concursos nacionales e internaciones, como Europan 7 Troms $\varnothing$, 0 el concurso de ideas para la Casa de la Juventud de Santoña, y exhibidos en exposiciones como la Bienal de Venecia, o la Bienal del Paisaje de las Islas Canarias. 